\title{
DECISION MAKING ON CAPITAL MARKETS USING NON- NUMERICAL MODEL BASED ON QUALITATIVE TRENDS
}

\author{
[Rozhodování na kapitálových trzích pomocí vágního modelu založeného na \\ kvalitativních trendech]
}

\author{
Tomáš Poláček ${ }^{1}$, Tomáš Meluzín ${ }^{2}$, Libor Chládek ${ }^{3}$ \\ ${ }^{1}$ Brno University of Technology, Faculty of Business and Management, Kolejni 4, 61200 Brno \\ Email:polacek@fbm.vutbr.cz \\ ${ }^{2}$ Brno University of Technology, Faculty of Business and Management, Kolejni 4, 61200 Brno \\ Email:meluzin@fbm.vutbr.cz \\ ${ }^{3}$ Brno University of Technology, Faculty of Business and Management, Kolejni 4, 61200 Brno \\ Email: chladek@fbm.vutbr.cz
}

\begin{abstract}
One of the main objectives of this study is to develop a qualitative model that will serve the decision makers' CFOs (chief financial officers), where, as a rule, it is decided without deeper processing of information many factors that affect each other significantly. Lack of appropriate statistical information in connection with turbulently changing environments suggests that further research is needed to extend existing IPO models based on statistical analyzes. The paper is using basic qualitative research of trends. A qualitative trend model can be developed under conditions when the relevant quantitative model must be heavily simplified. The key information input into IPO is expert knowledge. The solution of a trend model $M(X)$ is a set $S$ of scenarios where $X$ is the set of $n$ variables quantified by the trends. All possible transitions among the scenarios $\mathrm{S}$ are generated. An oriented transitional graph $\mathrm{G}$ has as nodes the set of scenarios $\mathrm{S}$ and as arcs the transitions $\mathrm{T}$. An oriented $\mathrm{G}$ path describes any possible future and past time behaviour of the IPO system under study. The case study presents a model based on integration of equationless relations using 8 variables e.g. Market condition, Recognisability or Liquidity risk. There are 17 scenarios S and 41 transitions $\mathrm{T}$ among them. All pairs of relationships are based on trends, either increasing, constant, or decreasing. The key input of the correct IPO timing analysis is based on the knowledge of experts traced from qualitative heuristics. The transition graph is a qualitative interpretation of all possible quantitative time series of all variables used in our IPO timetable and should be used as an effective tool to support CFO decisions.
\end{abstract}

Keywords: bankruptcy, capital markets, forecast, IPO, qualitative, transition, trend.

JEL classification: G32, G17

Received: 5.10.2018; Reviewed: 24.10.2018; 26.11.2018; Accepted: 6.3.2019

\section{Introduction}

In this study, is intend to offer a different point of view on decision making within the Initial public offering. Where there is no adequate statistical data or shortness of implying any mathematical function for sharp variables on IPO timing, is in this paper given solution by developing a qualitative model supporting chief financial officers (CFOs) when considering going public under conditions of emerging and underdeveloped capital markets. Recent academic theories as well as empirical research documented a wide range of factors that affect decision making on IPO timing in well-developed capital markets, Meluzín, Zinecker (2014), Meluzín et al. (2016).

Forecasting and Decision-making related to IPO are often based on models of unique systems. It means that conventional statistical methods, which are, directly or indirectly, related to the basic law of large numbers, are difficult or impossible to apply, see e.g. Sen, Singer, (1994). 
IPO experts do not use systematically mathematical/numerical models as the basic framework for their reasoning. Experts rely usually on knowledge represented by common-sense logic/reasoning.

\section{Information Shortages}

Deep knowledge items are such items which reflect generally accepted elements of the relevant theories, e.g. the law of gravity is a well-known example of a deep item. Unfortunately there are no IPO deep knowledge items.

A shallow knowledge item is a heuristic. It has many exceptions; see e.g. Lipmann, Bogen (1923). However, just recently developed computer programs can solve complex tasks including IPO problems, see e.g. Bredeweg, Salles (2009).

It means that knowledge items of different levels of subjectivity must be taken into consideration to develop the best possible model of a unique task under study. Therefore, many bankruptcy observations are required. However, they are not available. This is the reason why information non-intensive formal tools are used more and more frequently, see e.g. fuzzy and / or rough sets Dočekalová, Kocmanová, (2016); Meluzín et al., (2016); Bočková et al., (2012)

Common sense formalization has attracted attention long time ago; see e.g. Lipmann, Bogen, (1923), Bredeweg, Salles, (2009). Common sense algorithms based just on four values positive, zero, negative, anything - are studied in this paper.

Many IPO related knowledge items are available just as verbal descriptions based on trends: plus/increasing; zero/constant; negative/decreasing. For example:

If the net capital inflow is increasing, the trade surplus is also rising.

All pairwise relations $\mathrm{X}$ and $\mathrm{Y}$ given in Fig. 1 are trend relations. It means that nothing is quantitatively known.

Six examples of quantifier-less pairwise trend relations are given in Fig. 1.

Figure 1: Examples of trend pair-wise relations
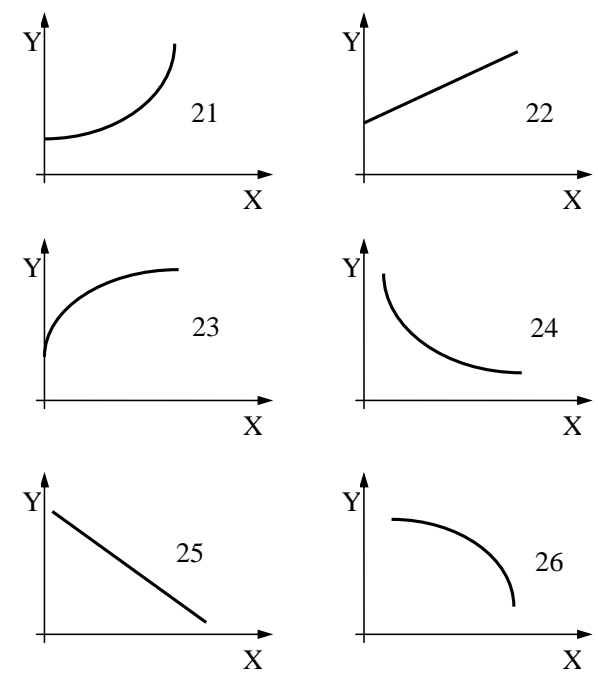

Source: own 
For example, the relation 22 indicates that:

- $\quad$ The relation $Y=f(X)$ is increasing

- $\quad$ There is a linear relationship between $\mathrm{Y}$ and $\mathrm{X}$

- If $\mathrm{X}=0$ then $\mathrm{Y}$ is positive.

The heuristic (1) is represented by the shape No. 21, see Figure 1.

Moreover the following two types of pairwise proportionalities / relations between variables X and $\mathrm{Y}$ are considered in this paper:

$\begin{array}{lll}\text { Support } & \text { X } & \text { Y } \\ \text { Reduce } & \text { X } & \text { Y }\end{array}$

Support An increase in (X) has a supporting effect on (Y)

Reduce $\quad$ An increase in $(\mathrm{X})$ has a reducing effect on $(\mathrm{Y})$.

The relations (3) are based just on the first derivatives $\mathrm{dY} / \mathrm{dX}$. The relations given Fig. 1 require trend quantification of the second derivative $\mathrm{d}^{2} \mathrm{Y} / \mathrm{dX}^{2}$. It means that the relations (3) are the most vague trend relations.

\section{Trend Models}

There are many different interpretations of trend concepts, see e.g. Stekler, Symington, (2016), Kamstr, Kennedy, (1998), Kim, Han, (2003). The trend concepts as it is used in this paper is based on four values: Positive + , Zero 0 , Negative - and any value represent by * (which is hardly used), see e.g. Bredeweg, (2009), Vicha, Dohnal, (2008):

$\begin{array}{llll}\text { Positive } & \text { Zero } & \text { Negative } & \text { Any Value } \\ + & 0 & - & *\end{array}$

An equationless trend model $\mathrm{M}$ is a set of $w$ pair-wise relations

$$
\begin{aligned}
& \mathrm{M}=\mathrm{P}_{s}\left(\mathrm{X}_{i}, \mathrm{X}_{j}\right) \\
& \mathrm{S}=1,2, \ldots \ldots \mathrm{W}
\end{aligned}
$$

Examples / shapes of the relations P (5) are given in Fig. 1.

An algorithm, which can be used to solve the model (5), is based on pruning of a specially generated tree of combinations. It is not the goal of this paper to describe such algorithm, as it is a purely mathematical combinatorial task, see e.g. Vicha, Dohnal, (2008).

The model (5) is solved and the set of $n$ dimensional scenarios is obtained $\mathbf{S}(\mathrm{n}, \mathrm{m})$. There are $m$ scenarios:

$$
\begin{aligned}
& \mathbf{S}(\mathrm{n}, \mathrm{m})=\left(X_{1}, \mathrm{D} X_{1}, \mathrm{DD} X_{1}\right),\left(X_{2}, \mathrm{D} X_{2}, \mathrm{DD} X_{2}\right), \ldots,\left(X_{n}, \mathrm{D} X_{n}, \mathrm{DD} X_{n}\right)_{j}, \\
& j=1,2, \ldots, m
\end{aligned}
$$

where, $\mathrm{D} X$ is the first and $\mathrm{DD} X$ is the second time trend derivatives. For example, the following three dimensional scenario, $\mathrm{n}=3(6)$ 


$$
\begin{array}{lll}
\mathrm{X}_{1} & \mathrm{X}_{2} & \mathrm{X}_{3} \\
(+++) & (+-0) & (+--)
\end{array}
$$

indicates that $\mathrm{X}_{1}$ is increasing more and more rapidly, $\mathrm{X}_{2}$ decreases linearly, $\mathrm{X}_{3}$ is decreasing more and more rapidly. All variables are positive - see the first symbol of all three triplets (7).

It is possible to take into consideration higher trend derivative, e.g. the third one DDDX. However, studied tasks are ill known and the third trend derivatives DDDX are not available.

Another simplification is that the second derivatives are ignored if the studied information items are so poorly known that the second derivatives DDX cannot be evaluated. If the second derivatives are ignored or unknown then the model (5) cannot be described by the shapes given in Fig. 1.

Trend proportionalities are therefore introduced, see (3). DTP is a direct trend proportionality and ITP is an indirect trend proportionality:

DTP If $X$ is increasing then $Y$ is increasing

If $X$ is decreasing then $\mathrm{Y}$ is decreasing $\quad \mathrm{DX}=\mathrm{DY}$

ITP If $X$ is increasing then $\mathrm{Y}$ is decreasing If $X$ is decreasing then $\mathrm{Y}$ is increasing

DTP represents the following three shapes, see Fig. 1: 21, 22, and 23. ITP represents 24, 25, and 26.

\section{Transitional Graphs}

The set of scenarios $\mathbf{S}$ (6) is not the only result of a trend modelling. It is possible to generate transitions among the set of scenarios.

Figure 2: A trend description of a quantitative oscillation

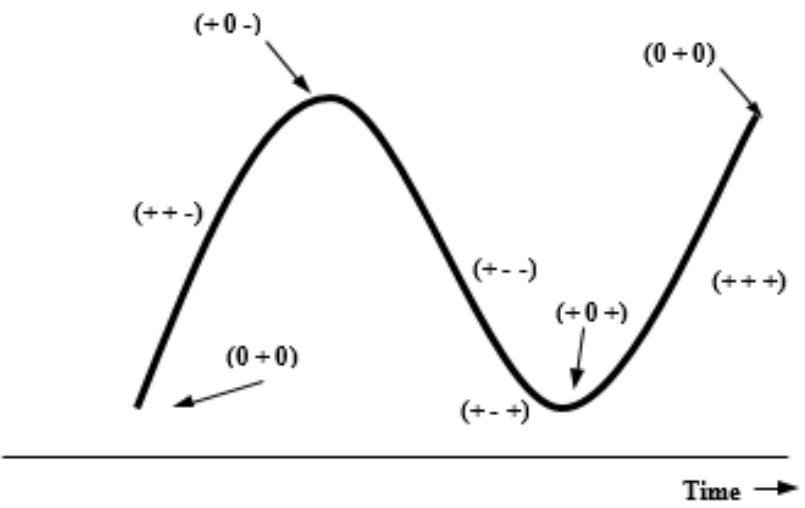

Source: own 
The triplets given in Figure 2 describe a broad spectrum of different oscillations, e.g. dumped oscillation or irregular oscillations with randomly or deterministically changing frequencies and / or amplitudes.

A complete set of all possible one-dimensional transitions is given in the following table:

Table 1: A list of some one-dimensional transitions

\begin{tabular}{||l|l|l|l|l|l|l|l|l|l||}
\hline & From & & To & Or & Or & Or & Or & Or & Or \\
\hline 1 & +++ & $\rightarrow$ & ++0 & & & & & & \\
\hline 2 & ++0 & $\rightarrow$ & +++ & ++- & & & & & \\
\hline 3 & ++- & $\rightarrow$ & ++0 & $+0-$ & +00 & & & & \\
\hline 4 & $+0+$ & $\rightarrow$ & +++ & & & & & & \\
\hline 5 & +00 & $\rightarrow$ & +++ & +-- & & & & & \\
\hline 6 & $+0-$ & $\rightarrow$ & +-- & & & & & & \\
\hline 7 & +-+ & $\rightarrow$ & +-0 & $+0+$ & +00 & $0-+$ & $00+$ & 000 & $0-0$ \\
\hline 8 & +-0 & $\rightarrow$ & +-+ & +-- & $0-0$ & & & & \\
\hline 9 & +-- & $\rightarrow$ & +-0 & $0--$ & $0-0$ & & & & \\
\hline
\end{tabular}

Source: own

For example, the third line of Tab. 1 indicates that it is possible to transfer the triplet $(++-)$ into the triplet $(+0-)$. This transition is not the only possible. There are two more possible transitions. Fig. 3 gives a trend description of an oscillation using the one dimensional triplets.

Any quantitative one-dimensional oscillation, see e.g. Fig. 1 and Fig. 2, can be represented by a simple oriented graph, see Fig. 3. There are 8 one-dimensional scenarios, $m=8, n=1(6)$. Any forecasting related to the oscillation Fig. 1 is trivial. For example the scenario $(++-)$ is transferred into the scenario (+ $0-)$, see Fig. 3.

Figure 3: Transitional one dimensional graph of an oscillation, see Tab. 1

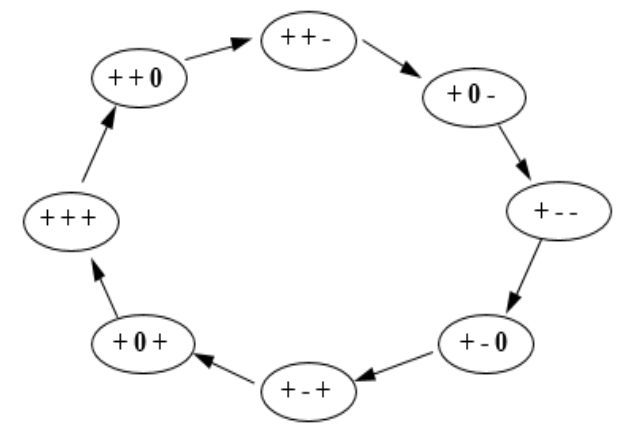

Source: own

An example of a more complex transitional graph is given in Fig. 4 . There are 5 scenarios, $m=$ 5 (6). The transitional graph in Fig. 4 is an example of an unsteady state behaviour of a more complex model (5).

If a forecaster accepts the model (5), then the corresponding transitional graph represents all possible trend forecasts and all possible trend histories to choose from; no feasible forecast can be overlooked / ignored. It means that the transitional graph is a generator of trend-based forecasts. 
Figure 4: Transitional graph based on the set of 5 scenarios

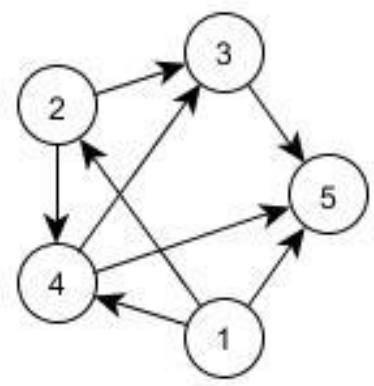

Source: own

Let us suppose that the scenario No. 4 is under study as a current forecasting root. The following paths are two-steps forecasts:

$$
\begin{aligned}
& \mathrm{S}_{4} \rightarrow \mathrm{S}_{3} \rightarrow \mathrm{S}_{5} \\
& \mathrm{~S}_{4} \rightarrow \mathrm{S}_{2} \rightarrow \mathrm{S}_{3}
\end{aligned}
$$

No other two steps behaviours / forecasts are possible.

The complete description of all past two steps histories is given in (10), if the current root is again the scenario No. 4, see Fig. 4.

$\mathrm{S}_{1} \rightarrow \mathrm{S}_{2} \rightarrow \mathrm{S}_{4}$

\section{Case Study}

The expert on decision making within IPO was contacted and after thoroughly interviewed the list of case study variables was generated for the hypothesis:

$\mathrm{H}_{0}$ : Hardly quantifiable variables have a major influence on the process of entering the capital markets.

$\begin{array}{ll}\text { Market condition } & M C D \\ \text { Competition } & C O M \\ \text { Political situation } & P O L \\ \text { Firm size } & F R S \\ \text { Recognisability } & R E C \\ \text { The Firm location } & F R L \\ \text { Issue size } & I S S \\ \text { Liquidity risk } & L Q R\end{array}$

\subsection{Description of the variables}

\section{Market condition MCD}

According to Businessdictionary is variable Market condition defined by characteristic of a new product, acquisition, new direction of the company or the venture capital that will be introduced, such as number of the competitors, level or intensity of competitiveness, and the market's growth rate. For the purpose of this study is the market condition crucial for further evaluation and implementation of the qualitative trends for decision making. 


\section{Competition $\quad \mathrm{COM}$}

Due to influence of the increasing competitiveness during the IPO through the different part of the economic cycle IPO spreads have declined significantly over time as the firms going public more recently are riskier, underwriting efforts have increased and recent IPOs are much larger than IPOs in the past. Controlling for time trends, larger IPOs have lower average spreads Mukesh, et al., (2008). The market for underwriting IPOs seems to be competitive with entry of new firms during the hot markets (Mukesh, et al. 2008). IPO incites significant contagion effect and competition effect in the market. This conclusion has been empirically supported by the exiting data Liang, (2012).

\section{Political situation POL}

It is not possible to analyse the IPO only through the micro environment by taking into account only market factors, it is necessary to look on the researched problem from "above" and implement the macro variable represent by political situation Radu, (2015). Every economic system must be integrated and harmonized with the country's continued development, a trend that reflects technological change and innovation, as well as political conflicts that lead to representing and changing interests and institutions. Therefore, it is important to include political factors to analyse the economic process Boyer, (2011) and to analyse to what extent and in what way the regime type of state administration affects its economic performance. Therefore, a vague variable such as the Political situation that enters the model and influences the relationship between the other variables is very important.

\section{Firm size $\quad$ FRS}

As was proven the Firm size has influence on oversubscription of initial public offerings (IPOs). The presence of firm size in influencing oversubscription further enables to test the information asymmetry argued by Beatty and Ritter (1986). The finding of the study by Tajuddin et al. shows that firm size has a significant and negative influence on oversubscription. The result indicates that large firm which have a proven records of accomplishment would have lower information asymmetry and do not need to under-price their IPOs to attract investors and decrease the probability of oversubscription.

\section{Recognisability REC}

This variable serves best for the successful entering into capital markets as the one of the first variables that is visible for the potential investors. For the good example can serve the case of initial public offering of the Facebook.

\section{The Firm location FRL}

The firm geographic location matters in IPOs because investors have a strong preference for newly issued local stocks and provide abnormal demand in local offerings. The study by Baschieri et at., (2016) provide consistent evidence that the isolated private firms have higher probability to go public, larger IPO under-pricing cross-sectional average and volatility, and less pronounced long-run under-performance. Similar but opposite evidence holds for the local concentration of the investor wealth

\section{Issue size ISS}

The issue size of a bond offering is the number of bonds issued multiplied by the face value. The issue size reflects both the borrowing needs of the entity issuing the bonds, as well as the market's demand for the bond at a yield that's acceptable to the issuer. 


\section{Liquidity risk LQR}

Liquid assets trade with small direct transaction costs such as commissions and bid-ask spreads, with a minimal time delay in execution, and with little or no price impact of the trade. Consistent with the notion that market liquidity affects individual stock prices, there is evidence that publicly listed firms trade at a premium over private companies, and that individual bid-ask spreads affect expected stock returns.

\section{Trend analysis}

The very nature of the variables (12) indicates that they are difficult to quantify, see e.g. Recognisability.

Let us suppose that there is a team of experts (managers for IPO)

From the obtained interview variables, the team developed the following model:

$\begin{array}{lllll}1 & 21 & \text { MCD } & \text { COM } & \text { see (8), see Figure 1 } \\ 2 & \text { DTP } & \text { MCD } & \text { POL } & \\ 3 & \text { ITP } & \text { COM } & \text { FRS } \\ 4 & 21 & \text { COM } & \text { LQR } \\ 5 & 25 & \text { COM } & \text { ISS } \\ 6 & \text { DTP } & \text { POL } & \text { FRL } \\ 7 & \text { DTP } & \text { FRS } & \text { ISS } \\ 8 & \text { ITP } & \text { REC } & \text { LQR }\end{array}$

There are 17 scenarios; $\mathrm{m}=17$

$\begin{array}{lllllllll}\# & \text { MCD } & \text { COM } & \text { POL } & \text { FRS } & \text { REC } & \text { FRL } & \text { ISS } & \text { LQR } \\ & \text { OC } & \text { OC } & \text { OC } & \text { UN } & \text { UN } & \text { UN } & \text { UN } & \text { OC } \\ 1 & +++ & +++ & +++ & +-- & +-- & +++ & +-- & +++ \\ 2 & ++0 & +++ & ++0 & +-- & +-- & ++0 & +-- & +++ \\ 3 & ++- & +++ & ++- & +-- & +-- & ++- & +-- & +++ \\ 4 & ++- & ++0 & ++- & +-0 & +-- & ++- & +-0 & +++ \\ 5 & ++- & ++- & ++- & +-+ & +-+ & ++- & +-+ & ++- \\ 6 & ++- & ++- & ++- & +-+ & +-0 & ++- & +-+ & ++0 \\ 7 & ++- & ++- & ++- & +-+ & +-- & ++- & +-+ & +++ \\ 8 & +0+ & +0+ & +0+ & +0- & +0- & +0+ & +0- & +0+ \\ 9 & +00 & +00 & +00 & +00 & +00 & +00 & +00 & +00 \\ 10 & +0- & +0- & +0- & +0+ & +0+ & +0- & +0+ & +0- \\ 11 & +-+ & +-+ & +-+ & ++- & ++- & +-+ & ++- & +-+ \\ 12 & +-0 & +-+ & +-0 & ++- & ++- & +-0 & ++- & +-+ \\ 13 & +-- & +-+ & +-- & ++- & ++- & +-- & ++- & +-+ \\ 14 & +-- & +-0 & +- & ++0 & ++- & +- & ++0 & +-+ \\ 15 & +-- & +-- & +-- & +++ & +++ & +-- & +++ & +-- \\ 16 & +-- & +-- & +-- & +++ & ++0 & +- & +++ & +-0 \\ 17 & +-- & +-- & +- & +++ & ++- & +- & +++ & +-+\end{array}$

There are 41 possible transitions among 17 scenarios (14). The transitional graph is very complex, see Fig. 5. 
Figure 5: Transitional graph based on the set of 17 scenarios (14)

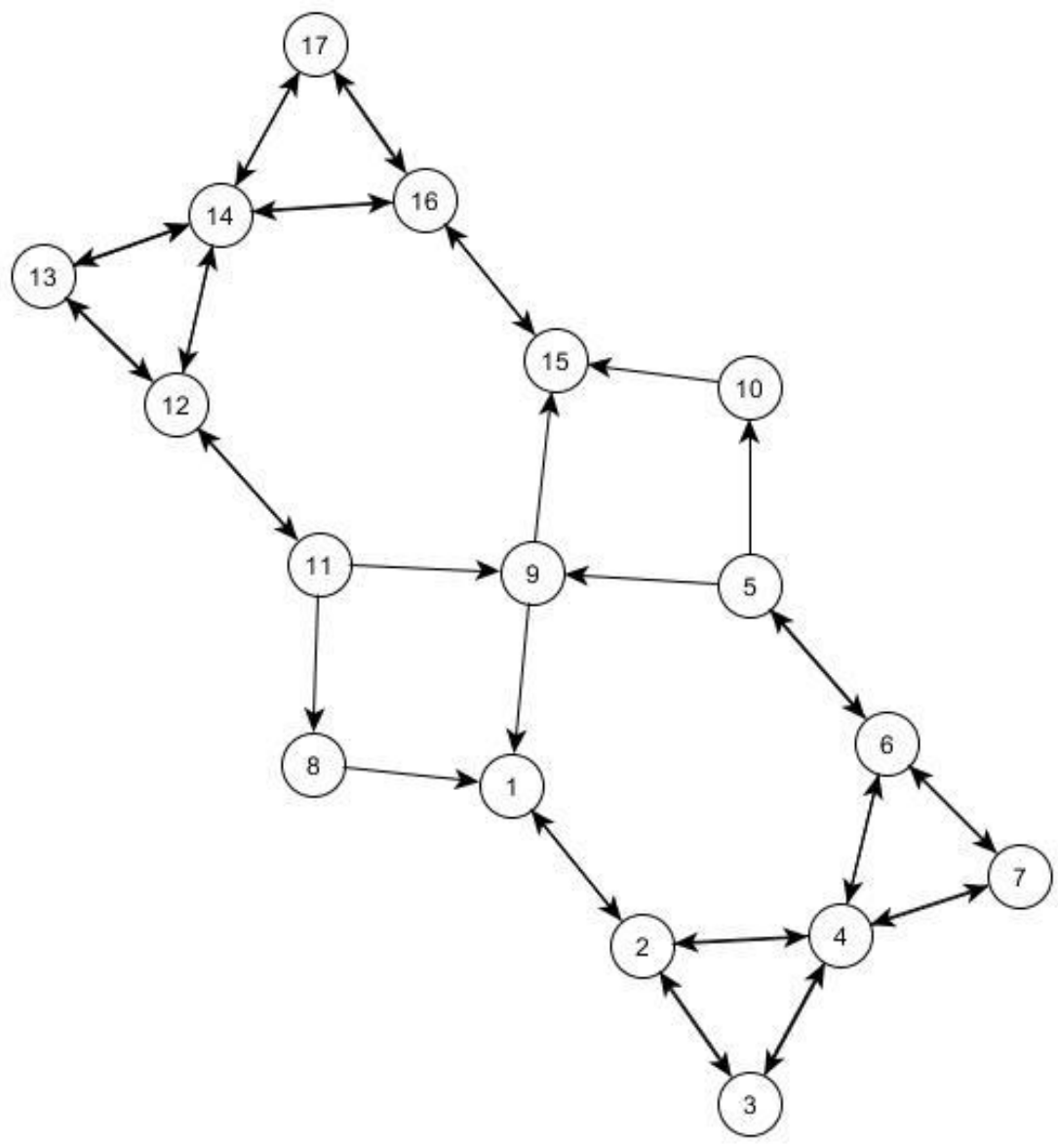

Source: own

The set of scenarios is the complete set of all possible scenarios, which satisfy the relations given in the model (13). For example, the scenario No. 8 has the entire first and the second derivatives zeros. It is therefore the qualitative steady state.

The set of scenarios (14) can be used to answer qualitative questions, for example:

Is it possible to? :

$\begin{array}{lllll}\text { Increase } & \text { REC } & \text { i.e. } & \mathrm{D}(\mathrm{REC})=+ & \text { AND } \\ \text { Increase } & \text { ISS } & \text { i.e } & \mathrm{D}(\mathrm{ISS})=+ & \text { AND } \\ \text { Decrease } & \mathrm{COM} & \text { i.e } & \mathrm{D}(\mathrm{COM})=- & \text { AND } \\ \text { Decrease } & \mathrm{LQR} & \text { i.e } & \mathrm{D}(\mathrm{LQR})=- & \end{array}$

If the studied query (15) is confronted with the set of scenarios (14) then it is clear that there are few scenarios that could be the target ones. It means that the answer to the query (15) is YES.

The variables (12) are into two subsets of variables $\mathrm{UN}$, OU:

UN (Under control of a decision maker): $\quad$ FRS, REC, FRL, ISS OC (Outside control): MCD, COM, POL, LQR 
This variable splitting (16) represents a point of view and is done on an ad hoc basis. It means that different decision makers can choose different UN and OC sub sets.

Let us suppose that the current situation / scenario under study corresponds to the scenario No. 3 (14). Let the current situation is the worst possible. The target variables ISS and LQR are at the worst position.

The worst trend description of entering capital markets are:
LQR Increase more and more rapidly
ISS Decreasing more and more rapidly
DSAT $=+\quad$ DDSAT $=+$
$\mathrm{DSOL}=-\quad$ DDSOL $=-$

The target scenario $\mathrm{S}_{\text {Target }}$ is the scenario No. 15; see (14) which represents the best possible IPO variant / scenario.

The target scenario 15 can be reached from the following scenarios in one-step; see e.g. Fig. 6:

Figure 6: A reachable sub graph of the complete transitional graph, see Fig. 5

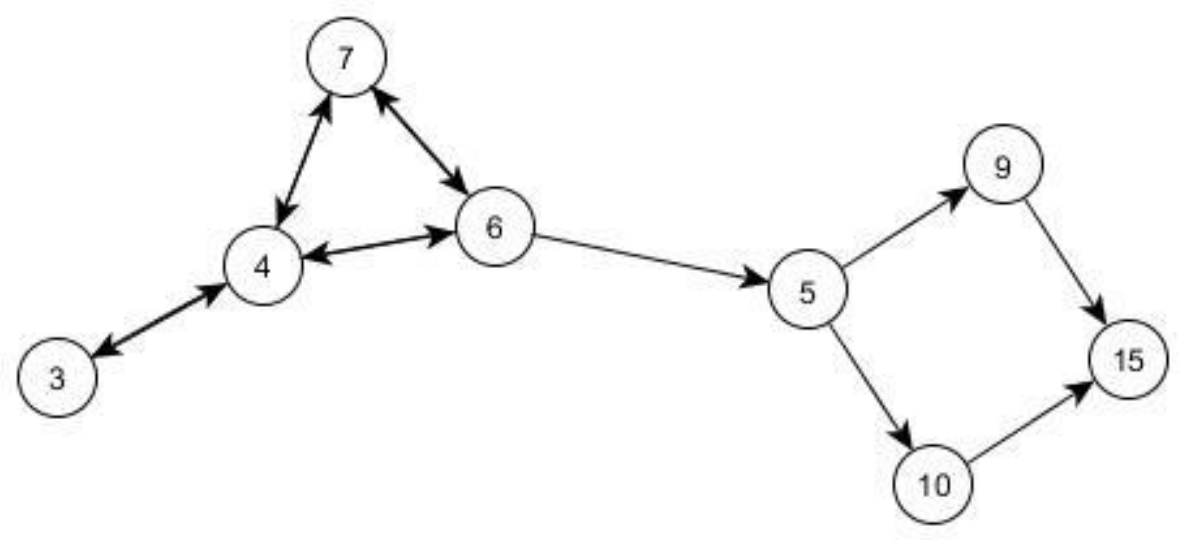

Source: own

The shortest path is the path leading from the worst scenario $S_{3}$ to the target scenario $S_{15}$; see e.g. Fig. 6:

$$
\mathrm{S}_{3} \rightarrow \mathrm{S}_{4} \rightarrow \mathrm{S}_{6} \rightarrow \mathrm{S}_{5} \rightarrow \mathrm{S}_{9} \rightarrow \mathrm{S}_{15}
$$

The sequence of scenarios is, see (18):

$\begin{array}{lllllllll}\# & \text { MCD } & \text { COM } & \text { POL } & \text { FRS } & \text { REC } & \text { FRL } & \text { ISS } & \text { LQR } \\ & \text { OC } & \text { OC } & \text { OC } & \text { UN } & \text { UN } & \text { UN } & \text { UN } & \text { OC } \\ 3 & ++- & +++ & ++- & +-- & +-- & ++- & +-- & +++ \\ 4 & ++- & ++0 & ++- & +-0 & +-- & ++- & +-0 & +++ \\ 5 & ++- & ++- & ++- & +-+ & +-+ & ++- & +-+ & ++- \\ 6 & ++- & ++- & ++- & +-+ & +-0 & ++- & +-+ & ++0 \\ 9 & +00 & +00 & +00 & +00 & +00 & +00 & +00 & +00 \\ 15 & +-- & +-- & +- & +++ & +++ & +- & +++ & +-\end{array}$

The scenario No. 3 represents the worst possible situation for entering the capital markets. The scenario No. 15 is the best variant according to a IPO managers. The path (19) leads from the very problematic situation to the optimal one. 
The decision maker will therefore decide on what is able to influence in the scenario if he identifies the state of process in initiative Scenario No. 15. The decision maker will evaluate whether or not he is able to change the transformation with his own power or the use of other methods if the variable that prevents the process from achieving the goal of successful IPO is beyond its control. If the variable is out of control of the decision maker, it is important to evaluate with which help he will be able to get through such a barrier in the process. If the scenario is clearly defined in what state the variable should be, the procedure is appropriately chosen. For example if it is necessary to increase the Recognisability it is obvious to use the help of outside marketing company to increase public awareness of this company. Of course, if, the POL (Political Situation) variable is a major variable that will obstruct successful completion, it will be very difficult to change this variable.

A decision maker has no free choice to change the variables (13). Some variables are not under his/her control (16). Therefore, there are variables selected by OC as out of control. It means that any forecast is partially based on available descriptions of $\mathbf{O C}$ variables.

\section{Conclusion}

At present, most of the techniques used for various analyses of entering on capital markets problems are of analytical and/or statistical natures. As a matter of fact these precise mathematical tools do not always contribute as much as is expected towards a full understanding of such tasks. With help of the trend modelling and the result from the case study is obvious that research question used in hypothesis (11) is valid. The hard-quantifiable variables have a major influence on successful IPO and it is necessary to count with them on the initialization of IPO. The are several other methods that can be used as alternative for the decision making within the vague variables such as fuzzy logic or using decision making trees with water probability or reconciliation Poláček, (2018).

A decision maker requires transparent and easy to understand explanations why and how different algorithms generate some forecasts. If formal tools are mathematically too demanding then it is very difficult to introduce them into the broad forecasting community. The trend transitional graphs can be explained using just elementary concepts of derivatives.

There are two main advantages of the trend based forecasting:

- It is possible to develop multidimensional models based on verbal knowledge items, e.g. heuristics. The set of trend scenarios is a superset of all meaningful scenarios, i.e. forecasts.

- No reasonable forecast can be missed if the analysis is based on a good trend model.

The main advantage of a qualitative IPO trend analysis is that no numerical values of constants and parameters are needed and the set of qualitative solutions is a superset of all meaningful scenarios, i.e. forecasts. No reasonable forecast can be missed if the analysis is based on a good qualitative model.

A decision maker requires transparent and easy to understand explanations why different algorithms generate some forecast. If formal tools are mathematically too demanding then it is very difficult to introduce them into the IPO community. Qualitative models are difficult to solve but easy to interpret. 
There are several unsolved problems of qualitative modelling and therefore results of qualitative approximations of some qualitative models can be problematic. If there is no scenario, $\mathrm{m}=0$ (6), then the studied model itself is not consistent. If there is no scenario then it is a reliable indication that a mistake was made in process of model developing meaning the variables are at some point in contradiction.

It is very probable that developments of relevant formal tools of artificial intelligence will have important consequences. Naïve physics and consequently algorithms based on common sense reasoning will be used in IPO models and related tasks more and more extensively.

In conclusion, the choice of variables for the behaviour of the model is a purely subjective opinion of the authors with the help of experts in the field.

\section{Acknowledgement}

This paper was supported by grants FP-J-18-4914 "Decisions on entering the capital markets using qualitative modelling methods.

\section{References}

[1] BREDEWEG, B. and P. SALLES, 2009. Qualitative models of ecological systems Editorial introduction. Ecol. Inform., Special Issue: Qualitative models of ecological systems 4, 261-262. doi:10.1016/j.ecoinf.2009.10.001

[2] TAJUDDIN, A. H. et al., 2017. The Effect of Institutional Investors on Oversubscription in the Malaysian IPOs. Market International Journal of Research in Management, Economics and Commerce, ISSN 2250-057X, Volume 07 Issue 08, Page 45-50

[3] BASCHIERI, G., A. CAROSI and S. MENGOLI, 2017. Initial Public Offerings and the Firm Location. Department of Management, Università Ca' Foscari Venezia Working Paper No. 2016/13.

[4] BEATTY, R. P. and J. R. RITTER, 1986. Investment banking, reputation, and the underpricing of initial public offerings. Journal of Financial Economics, 15(1), 213-232.

[5] BOČKOVÁ, N., Z. BROŽ and M. DOHNAL, 2012. Fuzzy model of relationship among economic performance, competitiveness and business ethic of small and medium - sized enterprises. Universitatis Agriculturae et Silviculturae Mendelianae Brunensis, roč. 2012, č. 4, s. 71-78. ISSN: 1211-8516.

[6] BOYER, D., 2011. Energopolitics and the Anthropology of Energy. Anthropology News [online]., 52(5), 5-7. DOI: 10.1111/j.1556-3502.2011.52505.x. ISSN 15416151.

[7] DELIS, M. D. and N. MYLONIDIS, 2015. Trust, happiness, and households' financial decisions. Journal of Financial Stability [online]., 20, 82-92. DOI: 10.1016/j.jfs.2015.08.002. ISSN 15723089.

[8] DOČEKALOVÁ, M. and A. KOCMANOVÁ, 2016. Composite indicator for measuring corporate sustainability. Ecological Indicators[online]. 61, 612-623. DOI: 10.1016/j.ecolind.2015.10.012.

[9] DOHNAL, M., 1985. Applications of a universal expert system in industry. Comput. Ind. 6, 115-121. doi:10.1016/0166-3615(85)90017-X 
[10] ECKBO, B. and E. NORLI, Liquidity risk, leverage and long-run IPO returns. Journal of Corporate Finance. 2005, 11(1-2), 1-35 [cit. 2018-12-03]. DOI: 10.1016/j.jcorpfin.2004.02.002. ISSN 09291199.

[11] FORBUS, K. D., (1984). Qualitative Reasoning About Physical Systems, Qualitative Process Theory 85-168. doi:10.1016/b978-0-444-87670-6.50006-6

[12] CHOUEIRY, B.Y., Y. IWASAKI and S. McILRAITH, 2005. Towards a practical theory of reformulation for reasoning about physical systems. Artif. Intell., Reformulation 162, 145-204. doi:10.1016/j.artint.2004.01.004.

[13] KAMSTR, M. and P. KENNEDY, 1998, Combining qualitative forecasts using logit, International Journal of Forecasting 14 83-93

[14] LIANG, CH. and R. YANG, 2012. IPO's Contagion Effect and Competition Effect. Fifth International Conference on Business Intelligence and Financial Engineering [online]. IEEE, s. 252-256. DOI: 10.1109/BIFE.2012.61. ISBN 978-1-4673-2092-4.

[15] LIPMANN, O. and H. BOGEN, 1996. Naive Physik. Arbeiten aus dem Instuut fur angewandte Psychologie in Berlin. Theoretische und experimentele Untersuchungen fuer die Feihigkeit zu intelligentem Handeln (Leipzig, Johann Ambrosius Barth)

[16] MELUZÍN, T., M. ZINECKER and N. LACE, 2016. Going Public: Key Factors to Consider by IPO Candidates on Emerging Markets of Poland and the Czech Republic. Engineering Economics, vol. 27, no. 4, p. 392-404. ISSN 1392-2785.

[17] MUKESH, B., H. CHEN and C. MAZUMDAR, 2008, Competition in IPO underwriting: Time series evidence, in Andrew H. Chen (ed.) Research in Finance, Volume 24. Emerald Group Publishing Limited, pp.1 - 25

[18] ORRELL, D. and P. McSHARRY, 2009. System economics: Overcoming the pitfalls of forecasting models via a multidisciplinary approach. Int. J. Forecast., Special section: Decision making and planning under low levels of predictability 25, 734-743. doi:10.1016/j.ijforecast.2009.05.002

[19] POLÁČEK, T. and M. DOHNAL, 2018. Qualitative Models of Bankruptcy Proceedings using Multi- Expert Complex Decision Making. PERSPECTIVES OF BUSINESS AND ENTREPRENEURSHIP, DEVELOPMENT IN DIGITAL AGE. 2017. s. 54-55. ISBN: 97880-214-5531- 3.

[20] RADU, M., 2015. The Impact of Political Determinants on Economic Growth in CEE Countries. Procedia - Social and Behavioral Sciences[online]. 197, 1990-1996. DOI: 10.1016/j.sbspro.2015.07.579. ISSN 18770428.

[21] SEN, P. K. and J. M. SINGER, 1994. Large Sample Methods in Statistics: An Introduction with Applications. CRC Press.

[22] STEKLER, H. and H. HILARY SYMINGTON, 2016. Evaluating qualitative forecasts: The FOMC minutes, 2006-2010, International Journal of Forecasting, 32, 559-570

[23] TOWNSEND, T., 2008, Mathematical psychology: Prospects for the 21st century: A guest editorial, Journal of Mathematical Psychology 52, pp 269-280

[24] VÍCHA, T. and M. DOHNAL, 2008. Qualitative identification of chaotic systems behaviours. Chaos, Solitons \& Fractals [online]., 38(1), 70-78. DOI: 10.1016/j.chaos.2008.01.027. ISSN 09600779. 